Published in final edited form as:

Cancer Discov. 2020 December 01; 10(12): 1797-1807. doi:10.1158/2159-8290.CD-20-0844.

\title{
Targeting metabolic plasticity and flexibility dynamics for cancer therapy
}

\author{
Sarah-Maria Fendt ${ }^{1,2}$, Christian Frezza ${ }^{3}$, Ayelet Erez ${ }^{4}$ \\ ${ }^{1}$ Laboratory of Cellular Metabolism and Metabolic Regulation, VIB-KU Leuven Center for Cancer \\ Biology, VIB, Herestraat 49, 3000 Leuven, Belgium \\ 'Laboratory of Cellular Metabolism and Metabolic Regulation, Department of Oncology, KU \\ Leuven and Leuven Cancer Institute (LKI), Herestraat 49, 3000 Leuven, Belgium \\ ${ }^{3}$ Medical Research Council Cancer Unit, University of Cambridge, Cambridge Biomedical \\ Campus, CB2 0XZ, UK. \\ ${ }^{4}$ Department of Biological Regulation, Weizmann Institute of Science, Rehovot, Israel.
}

\begin{abstract}
Cancer cells continuously rewire their metabolism to fulfil their need for rapid growth and survival whilst subject to changes in environmental cues. Thus, a vital component of a cancer cell lies in its metabolic adaptability. The constant demand for metabolic alterations requires flexibility, i.e. the ability to utilize different metabolic substrates, as well as plasticity, i.e. the ability to process metabolic substrates in different ways. In this review, we discuss how dynamic changes in cancer metabolism affect tumour progression and the consequential implications for cancer therapy.
\end{abstract}

\section{Introduction}

Since the original work of Otto Warburg in the 1920s that demonstrated cancer cells prefer glycolysis over mitochondrial respiration even under conditions of sufficient oxygen supply (Warburg 1956; Warburg, Wind, and Negelein 1927), multiple studies have shown that the metabolic reprogramming of cancer is not static, but rather a highly dynamic process. The essentiality and uniqueness of these metabolic alterations enabled new discoveries in cancer diagnosis and therapy and led to the designation of cancer metabolism as one of cancers' hallmarks (Hanahan and Weinberg 2011). Indeed, numerous metabolic alterations are coopted by cancer cells during tumour initiation and progression, to maximize cancer fitness to the ever- changing environmental cues (Faubert, Solmonson, and DeBerardinis 2020). Therefore, continuous metabolic adaptations are key for cancer cell growth and survival. These adaptations are achieved by coordinated intrinsic changes in gene expression leading to suppression and activation of enzymes, as well as by extrinsic fluctuations in the levels of metabolites, which directly induce or repress a specific metabolic pathway.

Correspondence to: Sarah-Maria Fendt; Christian Frezza; Ayelet Erez.

Correspondence to: sarah-maria.fendt@kuleuven.vib.be; CF366@mrc-cu.cam.ac.uk; ayelet.erez@weizmann.ac.il.

Authors declare no conflict of interest. SMF has received funding from Bayer, Merck BlackBelt Therapeutics and has consulted for Funds + . 
In this review we frame the nuances in the metabolic reprogramming during tumour progression as metabolic flexibility (the ability to use different nutrients) and plasticity (the ability to process the same nutrient differently) (Kelley and Mandarino 2000). In addition, we highlight the dynamic ability of metabolism during tumorigenesis as a target for improving response to cancer therapy and for overcoming resistance.

\section{A Metabolic flexibility and plasticity during cancer progression, an overview (Figure 1)}

As tumours grow and progress, cancer cells face changing microenvironments, which are composed of different nutrients, metabolites, and cell types. This happens at first because as the tumour proliferates and grows, differently vascularized areas arise, resulting in gradients of oxygen, available nutrients and in accumulation of tumour produced metabolites.

Consequently, and depending on the tumour type, metabolic intratumour heterogeneity can arise. In this respect it has been shown that within the same human lung cancer lesions, cancer cells in low perfused areas of the tumour relied on glucose for energy metabolism, while cancer cells in higher perfused areas preferred other nutrients, presumably lactate (Hensley et al. 2016).

A similarly high metabolic flexibility has also been recapitulated when switching cancer cells from an in vitro to an in vivo environment (Davidson et al. 2016), or when comparing the same tumour cells grown in two different organs (Christen et al. 2016). Such metabolic flexibility may be inherent to the heterogeneity of every cancer but also might be restricted to the cancer type and specific oncogenic mutations. Accordingly, it was found that in clear cell renal cell carcinoma (ccRCC), which are in $90 \%$ of the patients defined by Von HippelLindau (VHL) loss and a consequent pseudo-hypoxic state, cancer cells relied mostly on glucose and low activity of the tricarboxylic acid (TCA) cycle, as compared to lung and brain tumours (Courtney et al. 2018). It remains to be determined whether the low metabolic flexibility in ccRCC is caused by a decreased heterogeneity following the predominance of VHL mutations.

Nutrient availability to cancer cells is also influenced by the stroma. Accordingly, it has been observed that pancreatic ductal adenocarcinoma (PDAC) cells feed on alanine released from stroma-associated pancreatic stellate cells (Sousa et al. 2016). Consequently, targeting the neutral amino acid transporter SLC38A2 impaired PDAC growth (Parker et al. 2020). Similar stroma-associated pancreatic stellate cell-derived lysophosphatidylcholines supported PDAC membrane synthesis and growth signalling (Auciello et al. 2019). These and similar findings highlight that cancer cells can adapt but also trigger the release of certain nutrients from the stromal compartment.

Interestingly, it was further observed that such a conditioning of the nutrient environment by stromal cells also happens during pre-metastatic niche formation. In particular, primary breast tumour-secreted miR122 impaired glucose uptake in non-transformed cells, elevating glucose availability in the pre-metastatic niche of the lung, which ultimately increased the permissiveness of the niche for hosting metastasizing cancer cells (Fong et al. 2015). In line, there is increasing evidence that cancer cell metabolic flexibility can promote aggressiveness, ultimately leading to metastasis formation. Specifically, it was shown that lactate uptake in primary lesions correlated with aggressive oncological behaviour in human 
non-small cell lung cancer patients (Faubert et al. 2017). Mechanistically, it was found that lactate consumption supported the anti-oxidant protection of disseminating cancer cells (Tasdogan et al. 2020), which is important for increasing survival of metastasizing cancer cells in the circulation (Elia, Doglioni, and Fendt 2018). Similarly, stimulating palmitate consumption in cancer cells, resulting in the expression of the fatty acid binding protein CD36, boosted the metastatic potential of human oral cancer orthotopic mouse models, and CD36 expression correlated with poor prognosis in multiple cancers (Pascual et al. 2017). In addition, asparagine availability has been found to boost metastasis formation in experimental breast cancer mouse models (Knott et al. 2018). Hence, nutrient flexibility may contribute to cancer progression.

Interestingly, while flexibility seems widely present in the heterogeneous environment of the primary tumour, metastasizing cancer cells seem to lose this flexibility, creating a dependence on a particular nutrient. In line, it was found that inhibiting the lactate transporting protein monocarboxylate transporter 1 (MCT1) and CD36 in patient-derived mouse models of melanoma and oral squamous cell carcinomas, respectively, impaired metastasis formation but did not affect primary tumour growth (Tasdogan et al. 2020; Pascual et al. 2017). Similarly, simply restricting dietary asparagine during cancer cell dissemination also reduced metastasis formation (Knott et al. 2018). This feature of lost metabolic flexibility seems to be continued when cancer cells reach distant organs. Breast cancer cells that seed in the lung environment remodel the extracellular matrix to create a permissive niche (Gilkes et al. 2013). For this activity, collagen prolyl-4-hydroxylase (P4HA) is required. While this enzyme is highly transcriptionally regulated (Gilkes, Semenza, and Wirtz 2014), it was recently discovered that pyruvate uptake from the extracellular space via MCT2 is required for P4HA-dependent collagen hydroxylation and for metastasis outgrowth in breast cancer mouse models (Elia et al. 2019). Notably, the extracellular pyruvate requirement of cancer cells for remodelling the extracellular matrix of the metastatic niche was not dependent on carbon contribution but rather on regulation via metabolite concentrations leading to alanine aminotransferase (ALT2, also known as GPT2)dependent production of a-ketoglutarate (Elia et al. 2019). Moreover, it has been found that proline catabolism serves as an energy source in breast cancer cells colonizing the lung, but not in the corresponding primary tumours (Elia et al. 2017). Interestingly, dependency on proline catabolism was at least in vitro only found during colonization but not once colonies had formed, suggesting that the dependence on proline catabolism may be a transient event during metastasis formation.

The dependencies on certain nutrients or nutrient inflexibility during metastasis may be explained by several mechanisms. First, a reduced heterogeneity within metastasizing cancer cells may explain nutrient inflexibility, i.e. the cancer subpopulation most capable of metastasis formation may inherently not be able to use a certain nutrient. Thus, on the macroscopic level, primary tumours show flexibility due to heterogeneity while metastases may have lost it due to reduced heterogeneity. Alternatively, the phenotypic changes required for metastasis formation may result in the dependency of cancer cells on certain nutrients. In this case, nutrient flexibility in established secondary tumours should be similar to primary tumours and thus nutrient inflexibility would be transient. Lastly, nutrient inflexibility may be simply induced by the environment and thus the lack of certain nutrients 
in a given environment may induce nutrient inflexibility. Further studies are needed to address the nature of nutrient inflexibility in (metastatic) cancer cells. These include a further mechanistic understanding to what extent metabolic heterogeneity and microenvironment-dependent metabolic inflexibility can explain organ-specific metastasis patterns. An important additional and clinically relevant question is whether metastases regain a certain metabolic flexibility and thus to what extent metastasis prevention versus treatment can be achieved with the above-described mechanisms.

Besides metabolic flexibility, metabolic plasticity also contributes to effective cancer progression. Interestingly, the metabolic mode cancer cells use to increase their energy production during metastatic outgrowth seems to be dependent on microenvironmentinduced plasticity. Specifically, it was found that breast cancer cells metastasizing to the lung show a peroxisome proliferator-activated receptor gamma coactivator 1-alpha (PGC-1a)dependent bioenergetic plasticity in glucose metabolism (Andrzejewski, Klimcakova, Johnson, Tabariès, et al. 2017), while the same breast cancer cells metastasizing to the liver required glycolytic energy production (Dupuy et al. 2015). In the latter case, silencing of pyruvate dehydrogenase kinase 1 (PDK1), which shifts cells from glycolytic to mitochondrial energy production, prevented breast cancer-derived liver but not lung metastasis (Dupuy et al. 2015). In addition, cancer cell origin seems to alter the preferred energy production of cancer cells colonizing a distant organ. Accordingly, it has been shown that colorectal cancer cells metastasizing to the liver have the plasticity to scavenge extracellular bioenergetics through secretion of creatine kinase, brain-type (CKB) to the extracellular space (Loo et al. 2015).

The features of the surrounding extracellular matrix also contribute to cancer plasticity. While non-transformed cells die of anoikis once they lose matrix attachment, metastasizing cancer cells can activate antioxidant pathways to evade anoikis (Piskounova et al. 2015b; Le Gal et al. 2015; Tasdogan et al. 2020; Labuschagne et al. 2019). In addition, it has been found that matrix detached cancer cells of different origin can fuel glutamine carbon into reductive carboxylation (Jiang et al. 2016; Labuschagne et al. 2019), and that basal-like breast cancer cells activate the gluconeogenic enzyme fructose bisphosphatase 1 (FBP1) (Dong et al. 2013) to increase their ROS scavenging capacity. In line with these findings, metastasizing breast cancer cells can sustain a-ketoglutarate levels through activation of ALT2 (Elia et al. 2019), rather than the enzyme glutamine dehydrogenase (GDH), which is frequently used by non-transformed cells and primary cancer cells. Targeting ALT2 consequently greatly impaired metastasis formation in experimental breast cancer mouse models (Elia et al. 2019).

While the examples above imply the existence of metabolic plasticity, they could also be explained by a metabolic switch creating inherently a dependency on the newly activated pathway. To further disentangle metabolic plasticity from metabolic switching during cancer progression, metabolic pathways with dual activity in primary tumours could be studied. A prominent example of metabolic plasticity in primary tumours is the use of fatty acid desaturase 2 (FADS2)-mediated sapienate production in parallel to stearoyl-CoA desaturase-1 (SCD1)-mediated palmitoleate production to generate mono-unsaturated fatty acids from palmitate (Vriens et al. 2019; Triki et al. 2020). Here, neither the inhibition of 
FADS2 nor SCD1 blocks proliferation of certain cancer cells while the dual inhibition of both enzymes leads to impairment of proliferation. However, how this plasticity may change during metastasis formation remains to be determined. Thus, it will be important to define comprehensively to what extent true metabolic plasticity (compared to metabolic switching) contributes to metastasis formation and whether this plasticity is transient or stable and therefore can be exploited to prevent and treat metastases.

\section{B Mitochondrial plasticity in tumour progression}

A recent single-cell assessment of gene expression of metabolic enzymes from tumour tissue revealed a high degree of heterogeneity, whereby the expression of mitochondrial enzymes exhibited the highest variability within the same tumour (Xiao, Dai, and Locasale 2019). In support of this finding, a pioneering effort to generate a new sensor for mitochondrial potential, a read-out of mitochondrial health in vivo, showed that in human and mouse lung cancer, mitochondrial function is highly heterogeneous (Momcilovic et al. 2019) and correlates with different glycolytic subtypes. Whether this bioenergetic signature changes over time during tumour progression is currently unclear. Yet, it was shown that during cancer cell extravasation, melanoma cells expressing low levels of PGC1a, a master regulator of mitochondrial function, are selected for survival, and when they colonize the lungs, PGC1a levels are re-established (Luo et al. 2016). Of note, the PGC1a-low population showed enhanced migration in vitro and metastasis in vivo, whilst PGC1a-high population drives a proliferative phenotype in both the primary tumour and in the metastatic node (Luo et al. 2016). A similar connection between PGCla levels, mitochondrial function and metastasis was observed in prostate and renal cancers, associating with poor outcome (Torrano et al. 2016; LaGory et al. 2015), (Table 1). These results are in line with the observation that mtDNA depletion in human tumours, which is generally associated with bioenergetic defects, is linked with poor patient prognosis in several human cancers (Reznik et al. 2017). Yet, it should be noted that the connection between mitochondrial defects and metastasis does not apply to all cancer types. For instance, in breast cancer it has been demonstrated that metastatic cells exhibit increased mitochondrial biogenesis and respiration (LeBleu et al. 2014) and bioenergetic efficiency (Andrzejewski, Klimcakova, Johnson, Tabaries, et al. 2017) (Table 1). These results indicate a requirement for PGC1a and mitochondrial activity for metastasis. Consistent with this view, very recent findings indicate that another component of mitochondrial fitness, mitochondrial morphology, is required for angiogenesis and metastasis, and the genetic ablation of OPA1, a master regulator of mitochondrial fusion, abolished metastasis in mouse models of melanoma (Herkenne et al. 2020).

From a mechanistic point of view, the connection between mitochondrial function and cancer progression has been elusive. A seminal paper in 2008 provided the first line of evidence that replacing mitochondria with mitochondria from a metastatic cell line could transfer its aggressiveness (Ishikawa et al. 2008). Here, they ascribed the increased aggressiveness provided by metastatic mitochondria to increased oxidative stress. However, the putative roles of ROS in metastasis have been challenged and appear more complex and dependent on tumour stage (see below). Another hypothesis is that the metabolic changes that arise from a specific mitochondrial dysfunction could support metastasis. In support of 
this scenario, we recently showed that the gradual increase in mtDNA heteroplasmy of a mtDNA mutation of ATP6 is directly associated with EMT and increased migration (Gaude et al. 2018). We proposed that the loss of mitochondrial function caused by high levels of heteroplasmy activates glycolysis and the coupling between the glycolytic enzyme GAPDH and the enzyme malate dehydrogenase 1 (MDH1), which we found to co-localize with the cytoskeleton. Although the molecular details have yet to be defined, it is possible that mitochondrial dysfunction could prompt a metabolic rewiring that facilitates cell motility and migration. Nevertheless, it should be underscored that rather than a complete dysfunction, the extent of mitochondrial dysfunction we assessed was limited to $80 \%$ of mtDNA heteroplasmy, and cells still exhibited mitochondrial-dependent respiration. Therefore, it is possible that a stronger mitochondrial defect could be counterproductive for cancer cell growth and motility. Indeed, mutations that hamper mitochondrial function significantly could be detrimental to cancer cells, as indicated by the relatively benign nature of oncocytomas, tumours characterized by a significant mitochondrial suppression (De Luise et al. 2017), and by the fact that tumours generated by cells devoid of mtDNA uptake healthy mitochondria from neighbouring cells to support pyrimidine biosynthesis (Bajzikova et al. 2019). Consistent with this view, maintaining an appropriate turnover of mitochondria via autophagy is essential for cancer, and when autophagy is inhibited, the accumulation of unhealthy mitochondria leads to cancer cell demise (reviewed in (Kimmelman and White 2017)).

Another possible advantage that mitochondrial dysfunction provides to cancer could be induction of an anabolic/antioxidant metabolic rewiring that supports growth and survival under harsh environmental conditions by reducing cancer dependency on oxygen consumption for ATP generation. Indeed, a reduction in mitochondrial respiration together with a parallel increase in glycolysis can enable cancer cells to survive when the tumour is poorly vascularized and the supply of oxygen becomes limited. This hypothesis is supported by the observation that activating oxygen consumption in cancer cells by the expression of uncoupling protein 1 can reduce cancer cell survival (Chen et al. 2009). A corollary to this metabolic reprogramming is the accumulation of metabolites that have signalling roles and can elicit a phenotype switch that supports survival and metastasis. For instance, it was shown that the accumulation of mitochondrial metabolites such as $2 \mathrm{HG}$, fumarate, and succinate, which are known to increase under conditions of poor oxygenation, could trigger EMT (reviewed in (Sciacovelli and Frezza 2017).

It is also possible that dysregulation of mitochondrial function during tumour progression has non-cell autonomous functions and can affect the tumour microenvironment. Indeed, tumours that are deficient for Complex I, despite their slow proliferation, induce macrophage infiltration into the tumour and increase tumour malignancy (Kurelac et al. 2019).

Finally, ROS have long been considered unwanted by-products of mitochondrial metabolism. More recently, ROS have been suggested to function as important signalling molecules, implicated in many diseases including cancer. However, their role in tumorigenesis is far from clear, due to both technical challenges in their detection and modulation, especially in vivo, and due to the fact that their function seems to depend on 
tumour stage. During the early phases of tumorigenesis, ROS appear to be mutagenic, and therefore, they support transformation. Recent evidence indicates that ROS increase upon transformation but their levels are kept in check by antioxidant programmes such as that orchestrated by NRF2 (DeNicola et al. 2011). Independent experiments showed that mitochondrial ROS are essential for Kras-mediated tumorgenicity and anchorageindependent growth (Weinberg et al. 2010). Of note, cells deficient in mitochondrial DNA do not generate ROS and fail to grow in an anchorage-independent manner (Weinberg et al. 2010). Therefore, evidence indicates that ROS increase upon transformation and support oncogenic functions, but their lethal effects need to be counteracted by antioxidant programmes. Their role in tumour progression is even more debated. The increased ROS generation by dysfunctional mitochondria was initially linked with cancer metastasis in the above-described mitochondria swap experiment between normal and highly aggressive cancer cells (Ishikawa et al. 2008). Of note, antioxidants appeared to reduce the metastatic potential of these cybrid cancer cells in vivo. Only a year later, it was reported that during cell detachment, one of the key steps of tumour progression that precedes metastasis, cells experience a burst of oxidative stress, which, if left unchecked, can lead to cell demise (Schafer et al. 2009). Of note, antioxidants appeared to increase the chances of survival of detached cells. To sum up these two lines of evidence, on one hand, ROS increase malignancy; on the other hand, too much ROS is toxic for cancer cells detached from their matrix, with an opposite metastasis-promoting effect of antioxidants. Of note, it is still unclear why cells that detach from the matrix experience this burst in ROS, but it is possible that changes in metabolism elicited by alterations of cellular mechanics are responsible for it.

These two apparently contradicting pieces of evidence revealed that the role of ROS in cancer progression is likely context dependent. For instance, in the effort to elucidate the role of ROS in tumour progression, Porporato and colleagues found that mitochondrialderived superoxide, caused by either the suppression of mitochondrial function or mitochondrial overload, increases aggressiveness and metastasis in vivo (Porporato et al. 2014). Of note, the authors found that this increased migration involved the protein tyrosine kinases Src and Pyk2 as downstream effectors and was blunted by mitochondria-specific antioxidants. However, in a model of melanoma, it was found that metastasis activates an antioxidant programme to survive and antioxidants increase the efficiency of metastasis (Piskounova et al. 2015a). Here, the authors concluded that oxidative stress limits the formation of distant metastasis in vivo. Consistent with this view, it was found that melanoma metastases rely on lactate not only as an energy substrate but also as a source of reducing power via the activation of the oxidative arm of the pentose phosphate shunt (Tasdogan et al. 2020). This work is consistent with the finding that antioxidants increase rate of metastasis in melanoma in preclinical settings (Le Gal et al. 2015). Overall, a scenario is emerging whereby ROS affect cancer cells in a dose- and stage-dependent fashion. During the early phases of tumorigenesis, increased ROS, possibly caused by dysregulation of mitochondrial function, could activate signalling cascades that promote transformation. Of note, at this stage, ROS could further shape the fate of early tumours by causing DNA damage and genome instability (Srinivas et al. 2019). During this phase, the antioxidant capacity of the cells may be sufficient to avoid cell death. Yet, when the tumour 
grows and cells start to detach from the matrix, cells experience a burst of oxidative stress. Cells that succeed in responding to this wave of oxidative stress have the ability to extravasate and efficiently metastasize. At both stages, the presence of antioxidant programmes is essential to avoid cell death. In support of this view, it was recently shown that in pancreatic cancer, the levels of the antioxidant protein TIGAR vary during tumour progression. During the early stages, high TIGAR levels are needed to cope with the oxidative stress caused by transformation. Yet, as the tumour progresses, decreasing levels of TIGAR appear to increase the malignancy of cancer cells, consistent with the selection for cells with higher ROS and higher invasive capacity. At a later stage, though, TIGAR levels go up again to buffer the oxidative stress experienced by metastatic cells (Cheung et al. 2020).

Overall, these accumulating data suggest that mitochondrial function plays a key role during tumour progression and that an important feature lies in the ability of the mitochondrial function level to be context specific. Therefore, an attractive therapeutic strategy could be to target mitochondrial potential for metabolic adaptability.

\section{Host metabolism affecting metabolic adaptation modalities at varying tumour stages}

Importantly, the host metabolism affects tumour metabolic adaptability potential, primarily by one's genetics. In congenital cancer predisposition syndromes, the kinetics of cancer development is promoted by an inherent metabolic rewiring caused by constitutive activation of signalling pathways and transcriptional programs that regulate anabolic metabolism i.e., RASopathies, Li-Fraumani syndrome and Cowden syndrome. In some syndromes, such as Proteus and Beckwith-Wiedemann syndromes, the uncontrolled cellular growth manifests as overgrowth of a specific tissue or of the whole body, as well as in tumour predisposition (Kamien et al. 2018). Several cancer predisposition syndromes involve mutations in metabolic genes that either cause cell toxicity leading to cancer, i.e., the development of hepatocellular carcinoma in patients diagnosed with tyrosinaemia type I (Erez and DeBerardinis 2015; Erez et al. 2011), or the accumulation of metabolites with oncogenic activity. For instance, in the hereditary cancer syndromes caused by germline mutations in SDH or FH, accumulation of the oncometabolites fumarate and succinate, respectively, have been proposed to cause cancerous transformation (Sciacovelli and Frezza 2016); (Sciacovelli et al. 2020). To what extent the host metabolism predisposes to cancer in these tumour predisposition syndromes is currently unknown. In the case of SDH/FH-deficient tumours, patients are heterozygous for SDH/FH mutations and it will be important to determine whether the remaining wildtype allele is sufficient to maintain host physiology. It is possible that in some tissues heterozygous loss of $\mathrm{SDH} / \mathrm{FH}$ might give rise to mitochondrial dysfunction and/or mild accumulation of fumarate/succinate, affecting host metabolism and possibly dysregulating the immune response, decreasing the ability of the host to clear out $\mathrm{SDH} / \mathrm{FH}$-deficient clones. Interestingly, mitochondrial dysfunction syndromes pose an increased cancer risk as can be seen in mitochondrial depletion syndromes (Alston et al. 2017).

Some congenital metabolic syndromes involve chronic changes in metabolic flux that recapitulate similar changes to those observed in cancer cells, including enhanced pentose 
phosphate pathway (PPP) activity, lactate production, and high synthesis of lipids and nucleotides, predisposing to tumorigenesis. For example, in glycogen storage disease type 1a, the deficiency in the glycolytic glucose-6-phosphatase complex leads to hypoglycaemia, lactic acidosis, hyperlipidaemia, and increased shunting via the PPP (Zois and Harris 2016).

In addition, changes in host metabolic capacities due to aging, diet, health status and physical activity can affect cancer progression either directly or indirectly via the microbiome, which can generate metabolites affecting tumorigenesis (Bhatt, Redinbo, and Bultman 2017). With age, degenerative changes in the host metabolism create an inflexible and less fertile environment, which may drive tumours to metastasize (DePinho 2000). Importantly, the surrounding fibroblasts in aged melanoma patients secrete high amounts of lipids that enable drug resistance; the rich lipid tumour microenvironment promotes the upregulation of the tumour fatty acid transport protein (FATP) 2, which supports mitochondrial metabolism and cancer cell survival under therapy-induced stress (Alicea et al. 2020).

The host health status is a crucial determinant of its cancer risk (Luo and Liu 2019). In patients with obesity, cancer development is facilitated by metabolic reprogramming caused by the prevalence of diabetes and insulin resistance, leading to IGF-1 overproduction and to enhanced shunting of glycolytic intermediates via the PPP (Slawson, Copeland, and Hart 2010) (Calle and Kaaks 2004). Oppositely, a caloric restriction diet which likely constrains metabolic adaptability, affects the signalling of IGF-1, phosphoinositide 3-kinase (PI3K), phosphatase and tensin homolog (PTEN) and mammalian target of rapamycin (mTOR), resulting in inhibition of cancer growth. Interestingly, alterations in the circadian clock, which centrally regulates daily rhythms of cellular metabolism, have been shown to predict poor survival in cancer patients and to associate with increased incidence of several cancers in shift workers (Filipski and Levi 2009). Furthermore, perturbations of circadian clock components led to increased c-Myc expression and to metabolic dysregulations, consequently promoting lung tumour progression and decreasing survival (Papagiannakopoulos et al. 2016).

Thus, host fitness determines ones capacity to accommodate cancer demands for nutrients, thus affecting cancer metabolic adaptability.

\section{A framework for the metabolic evolution of cancer (Figure 2)}

In the previous sections, we have highlighted some of most investigated metabolic pathways and how they contribute to tumour initiation and progression towards metastasis. However, the determinants of these metabolic changes are only poorly understood. Are they intrinsically present in the original tumour, or are they acquired during tumour evolution? We propose the following two scenarios to explain the adaptability of cancer. In the first scenario, an initial tumour mass is composed of phenotypically identical clones. Depending on nutrient and oxygen availability, and likely external forces, some cells will undergo a phenotypic switch that prepares them to face the new environment. Only cells that have sufficient metabolic flexibility and plasticity will survive, extravasate, and contribute to metastasis. In this scenario, the adaptability can be driven by (epi)genetic changes that modulate the expression of metabolic genes. In addition, external cues, such as nutrients or 
growth factors, can further regulate these metabolic enzymes. Interestingly, chromatin structure and function depend on the availability of ATP, methyl donors, and other metabolites (aKG, succinate, fumarate, etc) that regulate chromatin modifiers. Therefore, it is possible that when a group of cancer cells experience changes in nutrient availability, the resulting epigenetic and transcriptional response is what drives their adaptation phase. In this scenario, the resulting metabolic phenotype is plastic and can be reverted or further changed depending on the new metabolic niche the cancer cell will experience. Such a scenario is supported by experiments showing that consecutive reimplantations of secondary lesions into the primary site re-establishes the original metastatic phenotype (Piskounova et al. 2015b).

The second scenario relies on the intrinsic phenotypical heterogeneity of the tumour mass. Here, we postulate that within a tumour mass, genetically identical cancer cells exhibit an intrinsic variability in their metabolic phenotype. While this intrinsic metabolic heterogeneity can be initially "neutral", i.e. it does not enhance growth or survival in the primary tumour, it may give rise to clones that can adapt to a new, harsher metabolic environment. It is possible that only a few cells within the tumour tissue will have the appropriate metabolic configuration that enables survival, but these will be sufficient to either invade the tissue or extravasate. This scenario is supported by some experimental evidence. For instance, although demonstrated in silico, it has been proposed that metabolic changes during evolution may originate non-adaptively and emerge from pre-adaptations, which are by-products of other adaptive traits. In line with this hypothesis, almost a decade ago it was demonstrated that mutant Ras could generate sub-clones that express high levels of the glucose transporter Glut1. This condition, which does not provide a growth advantage when glucose is available, provides unique advantages to the mutant cells when glucose becomes scarce (Yun et al. 2009). Although it is unclear how this heterogeneity in the expression of Glut1 is maintained, it is possible that epigenetic mechanisms govern it. We speculate that additional mutations that "fix" this metabolic configuration might arise in the clonal population, allowing for the emergence of a stable clone. It is possible that the genetic heterogeneity observed in tumours arises as a combination of non-genetic pre-adaptations and subsequent fixation of the phenotype by mutations in the genome.

Additionally, recent papers suggest that it is the existence of cancer stem cells with inherently high metabolic plasticity that generates resistance to therapy by allowing dynamic transitioning between different metabolic phenotypes, enabling tumours to regain growth following therapy (Snyder et al. 2018). Indeed, it has been reported that cancer stem cells are able to switch to a glycolytic metabolism when OXPHOS is blocked (Chae and Kim 2018). Interestingly, a combined analysis of biological, biochemical, pharmacological, and genetic studies revealed that cancer stem cells' stemness may arise from metabolic events occurring in non- cancer stem cells. Specific metabolic hits are thought to affect chromatin organization and activate epigenetic programs involved in the metabolic-driven reprogramming of cancer stem cells (De Francesco, Sotgia, and Lisanti 2018). According to this, the identification of key metabolic processes involved in this reprogramming might be useful to identify and target cancer stem cell survival. 


\section{E Tumor metabolic reprograming contributes to therapeutic resistance}

Tumour metabolic plasticity and flexibility contribute to resistance in most types of anticancer therapy. Undoubtedly, one of the main contributors to this metabolic adaptability potential is genetic heterogeneity. Here, resistance evolves by clonal selection of a specific signaling pathway that promotes the required metabolic rewiring that can meet the stress imposed by the drug. Since most anti-cancer therapies target the uncontrolled proliferation of cancer cells, the purpose of the compensatory metabolic reprograming is to restore cancer cell survival and growth. This is best exemplified in chemo-resistance caused by plasticity in glucose metabolism. For example, following cisplatin chemotherapy, several key glycolytic enzymes as HK2, PFK, and PKM2, and glucose transporters as GLUT-1, are induced in cervical cancer by activating adenosine monophosphate-activated protein kinase (AMPK) signalling (Lin et al. 2019) (Botzer et al. 2016). This augmentation in glycolysis results in high levels of glycolytic intermediates for branching pathways such as the PPP that supports nucleotide synthesis and redox homeostasis. Importantly, the resultant high lactate secretion generates a hypoxic microenvironment that limits drug entry into the cells. In addition, increased glucose consumption by upregulation of glucose transporters cues the cell to glucose deprivation and activates the stress machinery to induce autophagy and escape apoptosis (Ma and Zong 2020). In parallel, AMPK also promotes glutamine metabolism, which by itself contributes to chemo-resistance by supplying substrates to the TCA cycle to preserve mitochondrial function and support cancer cell survival (Liu et al. 2012). Indeed, combining the chemotherapy cisplatin with metabolic inhibitors of glycolysis, such as 3BrPA (3-bromopyruvate) - a specific inhibitor of HK-2 kinase, increase chemotherapy efficacy (Ihrlund et al. 2008) (Fan et al. 2019). Increasing mitochondrial metabolism can also provide an escape route for cancer cell survival from the effects of therapy; more than half of melanoma patients with BRAF mutations and a consequent mitogen-activated protein kinase (MAPK) activation develop resistance to MAPK inhibitors that is dependent on mitochondrial OXPHOS (Zhang et al. 2016). Indeed, therapy combining a MAPK inhibitor with a Gamitrinib, a small molecule targeting the mitochondria, augmented the efficacy of MAPK inhibitor treatment in melanoma cells by inducing mitochondrial dysfunction and inhibiting tumour bioenergetics (Zhang et al. 2016).

The anticancer mechanism of antiangiogenic therapy is to reduce tumour vascularity and cause tissue hypoxia. Yet, inducing hypoxia triggers upregulation of HIF1 that can lead to worse outcomes in terms of resistance (Abdalla et al. 2018). HIF1 induces the expression of glycolysis-related genes such as GLUT1, GLUT3, PDK1, PKM2, PFKFB3, GYS1, ENO1, LDHA, HK2 and GAPDH, again enhancing glycolysis and its branching pathways (McIntyre and Harris 2015). In addition, hypoxia in the tumour microenvironment leads to lipolysis and release of free fatty acids, while in parallel, hypoxia increases fatty acid uptake by the tumour via upregulation of the fatty acid importer CD36 expression. Within tumour cells, hypoxia increases glutamine uptake, providing substrates for the TCA cycle for the synthesis of citrate and for ATP synthesis by OXPHOS. The resultant increase in ATP and metabolite levels supports tumour proliferation and contributes to cancer resistance (Cao 2019). Here again, combined therapy of nintedanib and 3PO, a selective glycolytic inhibitor of 6-Phosphofructo-2-kinase/fructose-2,6-bisphosphatase (PFKFB3), was synergistic in inhibiting tumour growth in a breast cancer model (Pisarsky et al. 2016). While the increase 
in glycolysis may be a general metabolic strategy for chemo resistance, other tumours including melanoma and haematological malignancies appear to increase OXPHOS in resistant clones (reviewed in: (Ashton et al. 2018)). For instance, in melanoma, the increase in OXPHOS in resistant clones is supported by PGC1a and is needed to buffer oxidative stress (Vazquez et al. 2013). In line with this finding, in chronic myeloid leukaemia, targeting mitochondrial function can eradicate therapy-resistant cells (Kuntz et al. 2017).

In some cancer therapy that target a selected metabolic vulnerability, resistance may occur when the nutrient circumstances change following therapy. Under the new conditions, cancer cells benefit from selecting for clones with re-programming of the targeted metabolic pathway. For example, in multiple human malignancies including melanoma, hepatocellular carcinoma, prostate cancers, osteosarcoma and mesothelioma, argininosuccinate synthetase 1 (ASS1) is silenced by epigenetic methylation. ASS1 is a urea cycle enzyme that outside the liver participates in the citrulline-arginine cycle for the generation of arginine and its downstream metabolites (Keshet et al. 2018). Silencing of ASS1 increases the availability of its substrate, aspartate, for the synthesis of pyrimidines that are utilized for DNA and RNA synthesis that support cell proliferation (Rabinovich et al. 2015). Tumours with ASS1 silencing are hence proliferative but in parallel, become arginine auxotrophic, meaning they cannot synthesize arginine and require extracellular arginine supplementation for survival. This metabolic vulnerability is taken advantage of for therapy; arginine starvation agents such as PEGylated arginine deiminase (ADI-PEG20) and human arginase 1, which degrade extracellular arginine, are in various stages of clinical trials (Long et al. 2016). Yet, resistance to arginine-degrading treatment develops and involves re-expression of ASS1 caused by binding of MYC to its promoter (Long et al. 2013). Such evolving resistance exemplifies the advantage of epigenetic flexibility over genetic rigidity determined by mutations.

Importantly, the tumour microenvironment can provide tumours with metabolites that enable metabolic plasticity and flexibility, leading to cancer resistance. Increasing autophagy and exosome secretion in the microenvironment can provide essential metabolites as amino acids, fatty acids and nucleic acids to support the metabolic flexibility required for cancer cell survival and growth under nutrient deprivation (Mowers, Sharifi, and Macleod 2017). The exosome cargo can also provide metabolic plasticity which affects tumour progression by carrying exosome-associated miRNAs to the tumour cell. For example, in malignant mesothelioma cells, miR-126, an angiogenesis inducer, can regulate cancer metabolism by decreasing the levels of its downstream target insulin receptor substrate-1, causing upregulation in the expression of oxidative stress defence and gluconeogenesis genes (Saber et al. 2020). The resultant increase in glucose yields a glycolytic shift, which supports a less malignant mesothelioma phenotype (Tomasetti et al. 2014).

Thus, metabolic adaptability is an important component in cancer resistance to therapy and targeting it directly will likely be therapeutically beneficial. An attractive therapeutic approach could be to exploit these metabolic features to enhance therapy by targeting cancer adaptive mechanisms in particular, cancer heterogeneity and the specific signaling molecules that enable metabolic rewiring. 


\section{F Future therapeutic directions to potentially target tumor metabolic adaptability features}

A reasonable strategy to target tumour heterogeneity is based on identifying and targeting driver mutations (i.e.,BRAF) or a signaling pathway shared by multiple mutations in the same cancer (i.e., mTOR). Here, although a single drug can target multiple clones, the majority of patients eventually develop resistance and hence combining these signaling inhibitor drugs with metabolic inhibitors will likely be more efficient (Karachaliou et al. 2015) (Magaway, Kim, and Jacinto 2019). Indeed, concurrent inhibition of BRAF and glycolysis, or a combination of MAPK and mitochondrial inhibitors, induces cell death in BRAF inhibitor-resistant melanoma cells (Parmenter et al. 2014) (Zhang et al. 2016).

Another approach to diminish tumour heterogeneity is to stress tumours to develop a metabolic dependency that sensitizes tumour cells to specific therapies. For example, methionine is essential for protein synthesis, one carbon metabolism and nucleotide synthesis, gene regulation by DNA methylation, as well as for redox metabolism, which are all essential for carcinogenesis (Kanarek, Petrova, and Sabatini 2020). Restricting methionine by diet has been shown to sensitize PDX models of colorectal cancer to chemotherapy with 5-fluorouracil (5-FU) (31367041). To identify drugs that are relevant for implementing this approach, a metabolic sensitivity assay can be added to high-throughput drug screens.

Another strategy for targeting cancer adaptability potential is to target cancer stem cells by for example, using antibodies against cancer stem cell-specific cell surface markers as CD20, CD52 etc., (Yang et al. 2020). Similarly, attempts at targeting specific proteins that enable the switch between different metabolic states may also prove to be an attractive strategy. For example, the heat shock protein 90 (HSP90) molecular chaperone controls metabolic rewiring through either direct binding to chromatin or via control of transcription factors and epigenetic effectors (Condelli et al. 2019). Indeed, HSP90 interacts with and modulates several signaling pathways involved in metabolic plasticity including c-Myc, HIF1a and AKT/PKB. HSP90 can also influence cancer metabolism by directly binding glycolytic enzymes as GAPDH and PKM2. Specifically, HSP90 mitochondrial isoform TRAP1 stabilizes the binding of HK2 to the mitochondrial voltage-dependent anion channel (VDAC), maximizing its activity, and also binds and inhibits the activity of the respiratory chain complex II (succinate dehydrogenase-SDH) (Masgras et al. 2017). Likewise, reintroducing wild-type p53 or inhibiting c-MET might decrease the metabolic flexibility potential (Desbats et al. 2020).

\section{G Conclusions (Figure 3)}

There is no doubt that tumour evolution is determined mostly by the pressure to supply its metabolic needs under changing environmental metabolic stresses. This ability for metabolic adaptation to fluctuating stresses should hence be regarded as tumour's metabolic Achilles Heel and therapies targeting this should be included in the future arsenal against cancer.

Notably, cancer cells' survival mechanisms such as metabolic adaptability are hijacked from normal cells. The signalling and metabolic pathways providing this metabolic adaptability are all used by normal cells, and especially by proliferating cells, under physiological 
conditions. Hence, in targeting cancers' metabolic plasticity and flexibility features, it may be challenging to balance between causing side effects and developing therapy resistance. Along these lines, accumulating papers suggest changing the goal of cancer management from cure to chronic disease. Here, the idea of treatment is to avoid inducing extreme stress on cancer cells that presumably select for more aggressive clones, and rather aim to restrict and control cancer growth. For this, one would need to continuously identify targetable molecular changes and tailor treatments that are predicted to be most effective against resistance and relapse. This may be achieved by monitoring cancer burden with imaging together with following the precise molecular signature of the evolving cancer using liquid biopsies and repeated sequencing (Beck and Ng 2014).

Undoubtedly, more preclinical research and clinical trials must be completed before such interventions become common practice in cancer therapy. In the optimal scenario, combinatory drugs will abolish cancer adaptability potential, while in the more realistic scenario, we should aim to restrict the ability of cancer to adapt as much as possible.

\section{Acknowledgments}

We acknowledge and thank the Weizmann Institute for providing financial and infrastructural support. AE is incumbent of the Leah Omenn Career Development Chair and is supported by research grants from the European research program (ERC818943), and from the Israel Science Foundation (860/18). AE received additional support from The Moross Integrated Cancer Center, Sagol Institute for Longevity Research, Adelis Foundation,Rising Tide Foundation, and from Manya and Adolph Zarovinsky. CF work is funded by the MRC Core award grant MRC_MC_UU_12022/6, the European research program (ERC819920), and CRUK Programme Foundation award C51061/A27453. S.-M.F. acknowledges funding from the European Research Council under the ERC Consolidator Grant Agreement n. 771486-MetaRegulation, FWO - Research Projects (G098120N and G088318N), KU Leuven - Methusalem Co-Funding and Fonds Baillet Latour.

\section{References}

Abdalla AME, Xiao L, Ullah MW, Yu M, Ouyang C, Yang G. Current Challenges of Cancer Antiangiogenic Therapy and the Promise of Nanotherapeutics. Theranostics. 2018; 8:533-48. [PubMed: 29290825]

Alicea GM, Rebecca VW, Goldman AR, Fane ME, Douglass SM, Behera R, Webster MR, Kugel CH, Ecker BL, Caino MC, Kossenkov AV, et al. Changes in Aged Fibroblast Lipid Metabolism Induce Age-dependent Melanoma Cell Resistance to Targeted Therapy Via the Fatty Acid Transporter FATP2. Cancer Discov. 2020

Alston CL, Rocha MC, Lax NZ, Turnbull DM, Taylor RW. The genetics and pathology of mitochondrial disease. J Pathol. 2017; 241:236-50. [PubMed: 27659608]

Andrzejewski S, Klimcakova E, Johnson RM, Tabariès S, Annis MG, McGuirk S, Northey JJ, Chénard V, Sriram U, Papadopoli DJ, Siegel PM, et al. PGC-1a Promotes Breast Cancer Metastasis and Confers Bioenergetic Flexibility against Metabolic Drugs. Cell Metab. 2017

Andrzejewski S, Klimcakova E, Johnson RM, Tabaries S, Annis MG, McGuirk S, Northey JJ, Chenard V, Sriram U, Papadopoli DJ, Siegel PM, et al. PGC-1alpha Promotes Breast Cancer Metastasis and Confers Bioenergetic Flexibility against Metabolic Drugs. Cell Metab. 2017; 26:778-87 e5. [PubMed: 28988825]

Ashton TM, McKenna WG, Kunz-Schughart LA, Higgins GS. Oxidative Phosphorylation as an Emerging Target in Cancer Therapy. Clin Cancer Res. 2018; 24:2482-90. [PubMed: 29420223]

Auciello, Francesca R; Bulusu, Vinay; Oon, Chet; Tait-Mulder, Jacqueline; Berry, Mark; Bhattacharyya, Sohinee; Tumanov, Sergey; Allen-Petersen, Brittany L; Link, Jason; Kendsersky, Nicholas D; Vringer, Esmee; , et al. A Stromal Lysolipid-Autotaxin Signaling Axis Promotes Pancreatic Tumor Progression. Cancer Discov. 2019; 9:617. [PubMed: 30837243] 
Bajzikova M, Kovarova J, Coelho AR, Boukalova S, Oh S, Rohlenova K, Svec D, Hubackova S, Endaya B, Judasova K, Bezawork-Geleta A, et al. Reactivation of Dihydroorotate DehydrogenaseDriven Pyrimidine Biosynthesis Restores Tumor Growth of Respiration-Deficient Cancer Cells. Cell Metab. 2019; 29:399-416 e10. [PubMed: 30449682]

Beck S, Ng T. C2c: turning cancer into chronic disease. Genome Med. 2014; 6:38. [PubMed: 24944585]

Bhatt AP, Redinbo MR, Bultman SJ. The role of the microbiome in cancer development and therapy. CA Cancer J Clin. 2017; 67:326-44. [PubMed: 28481406]

Botzer LE, Maman S, Sagi-Assif O, Meshel T, Nevo I, Yron I, Witz IP. Hexokinase 2 is a determinant of neuroblastoma metastasis. Br J Cancer. 2016; 114:759-66. [PubMed: 26986252]

Calle EE, Kaaks R. Overweight, obesity and cancer: epidemiological evidence and proposed mechanisms. Nat Rev Cancer. 2004; 4:579-91. [PubMed: 15286738]

Cao Y. Adipocyte and lipid metabolism in cancer drug resistance. J Clin Invest. 2019; 129:3006-17. [PubMed: 31264969]

Chae YC, Kim JH. Cancer stem cell metabolism: target for cancer therapy. BMB Rep. 2018; 51:31926. [PubMed: 29764565]

Chen Y, Cairns R, Papandreou I, Koong A, Denko NC. Oxygen consumption can regulate the growth of tumors, a new perspective on the Warburg effect. PLoS One. 2009; 4

Cheung EC, DeNicola GM, Nixon C, Blyth K, Labuschagne CF, Tuveson DA, Vousden KH. Dynamic ROS Control by TIGAR Regulates the Initiation and Progression of Pancreatic Cancer. Cancer Cell. 2020; 37:168-82 e4. [PubMed: 31983610]

Christen S, Lorendeau D, Schmieder R, Broekaert D, Metzger K, Veys K, Elia I, Buescher JM, Orth MF, Davidson SM, Grünewald TG, et al. Breast cancer-derived lung metastasis show increased pyruvate carboxylase-dependent anaplerosis. Cell Reports. 2016; 17:837-48. [PubMed: 27732858]

Condelli V, Crispo F, Pietrafesa M, Lettini G, Matassa DS, Esposito F, Landriscina M, Maddalena F. HSP90 Molecular Chaperones, Metabolic Rewiring, and Epigenetics: Impact on Tumor Progression and Perspective for Anticancer Therapy. Cells. 2019; 8

Courtney, Kevin D; Bezwada, Divya; Mashimo, Tomoyuki; Pichumani, Kumar; Vemireddy, Vamsidhara; Funk, Alexander M; Wimberly, Jennifer; McNeil, Sarah S; Kapur, Payal; Lotan, Yair; Margulis, Vitaly; , et al. Isotope Tracing of Human Clear Cell Renal Cell Carcinomas Demonstrates Suppressed Glucose Oxidation <em>In\& Vivo</em>. Cell Metab. 2018; 28:793800.e2. [PubMed: 30146487]

Davidson, Shawn M; Papagiannakopoulos, Thales; Olenchock, Benjamin A; Heyman, Julia E; Keibler, Mark A; Luengo, Alba; Bauer, Matthew R; Jha, Abhishek K; O’Brien, James P; Pierce, Kerry A; Gui, Dan Y; , et al. Environment Impacts the Metabolic Dependencies of Ras-Driven Non-Small Cell Lung Cancer. Cell Metab. 2016; 23:517-28. [PubMed: 26853747]

De Francesco EM, Sotgia F, Lisanti MP. Cancer stem cells (CSCs): metabolic strategies for their identification and eradication. Biochem J. 2018; 475:1611-34. [PubMed: 29743249]

De Luise M, Girolimetti G, Okere B, Porcelli AM, Kurelac I, Gasparre G. Molecular and metabolic features of oncocytomas: Seeking the blueprints of indolent cancers. Biochim Biophys Acta Bioenerg. 2017; 1858:591-601. [PubMed: 28115060]

DeNicola GM, Karreth FA, Humpton TJ, Gopinathan A, Wei C, Frese K, Mangal D, Yu KH, Yeo CJ, Calhoun ES, Scrimieri F, et al. Oncogene-induced Nrf2 transcription promotes ROS detoxification and tumorigenesis. Nature. 2011; 475:106-9. [PubMed: 21734707]

DePinho RA. The age of cancer. Nature. 2000; 408:248-54. [PubMed: 11089982]

Desbats MA, Giacomini I, Prayer-Galetti T, Montopoli M. Metabolic Plasticity in Chemotherapy Resistance. Front Oncol. 2020; 10:281. [PubMed: 32211323]

Dong C, Yuan T, Wu Y, Wang Y, Fan TW, Miriyala S, Lin Y, Yao J, Shi J, Kang T, Lorkiewicz P, et al. Loss of FBP1 by Snail-mediated repression provides metabolic advantages in basal-like breast cancer. Cancer Cell. 2013; 23:316-31. [PubMed: 23453623]

Dupuy, Fanny; Tabariès, Sébastien; Andrzejewski, Sylvia; Dong, Zhifeng; Blagih, Julianna; Annis, Matthew G; Omeroglu, Atilla; Gao, Dongxia; Leung, Samuel; Amir, Eitan; Clemons, Mark; , et al. PDK1-Dependent Metabolic Reprogramming Dictates Metastatic Potential in Breast Cancer. Cell Metab. 2015; 22:577-89. [PubMed: 26365179] 
Elia, Ilaria; Broekaert, Dorien; Christen, Stefan; Boon, Ruben; Radaelli, Enrico; Orth, Martin F; Verfaillie, Catherine; Grünewald, Thomas GP; Fendt, Sarah-Maria. Proline metabolism supports metastasis formation and could be inhibited to selectively target metastasizing cancer cells. Nat Commun. 2017; 8

Elia, Ilaria; Doglioni, Ginevra; Fendt, Sarah-Maria. Metabolic Hallmarks of Metastasis Formation. Trends in Cell Biology. 2018; 28:673-87. [PubMed: 29747903]

Elia, Ilaria; Rossi, Matteo; Stegen, Steve; Broekaert, Dorien; Doglioni, Ginevra; van Gorsel, Marit; Boon, Ruben; Escalona-Noguero, Carmen; Torrekens, Sophie; Verfaillie, Catherine; Verbeken, Erik; , et al. Breast cancer cells rely on environmental pyruvate to shape the metastatic niche. Nature. 2019; 568:117-21. [PubMed: 30814728]

Erez A, DeBerardinis RJ. Metabolic dysregulation in monogenic disorders and cancer - finding method in madness. Nat Rev Cancer. 2015; 15:440-8. [PubMed: 26084394]

Erez A, Shchelochkov OA, Plon SE, Scaglia F, Lee B. Insights into the pathogenesis and treatment of cancer from inborn errors of metabolism. Am J Hum Genet. 2011; 88:402-21. [PubMed: 21473982]

Fan T, Sun G, Sun X, Zhao L, Zhong R, Peng Y. Tumor Energy Metabolism and Potential of 3Bromopyruvate as an Inhibitor of Aerobic Glycolysis: Implications in Tumor Treatment. Cancers (Basel). 2019; 11

Faubert B, Solmonson A, DeBerardinis RJ. Metabolic reprogramming and cancer progression. Science. 2020; 368

Faubert, Brandon; Li, Kevin Y; Cai, Ling; Hensley, Christopher T; Kim, Jiyeon; Zacharias, Lauren G; Yang, Chendong; Do, Quyen N; Doucette, Sarah; Burguete, Daniel; Li, Hong; , et al. Lactate Metabolism in Human Lung Tumors. Cell. 2017; 171:358-71.e9. [PubMed: 28985563]

Filipski E, Levi F. Circadian disruption in experimental cancer processes. Integr Cancer Ther. 2009; 8:298-302. [PubMed: 20042408]

Fong, Miranda Y; Zhou, Weiying; Liu, Liang; Alontaga, Aileen Y; Chandra, Manasa; Ashby, Jonathan; Chow, Amy; O’Connor, Sean Timothy Francis; Li, Shasha; Chin, Andrew R; Somlo, George; , et al. Breast-cancer-secreted miR-122 reprograms glucose metabolism in premetastatic niche to promote metastasis. Nat Cell Biol. 2015; 17:183-94. [PubMed: 25621950]

Gaude E, Schmidt C, Gammage PA, Dugourd A, Blacker T, Chew SP, Saez-Rodriguez J, O'Neill JS, Szabadkai G, Minczuk M, Frezza C. NADH Shuttling Couples Cytosolic Reductive Carboxylation of Glutamine with Glycolysis in Cells with Mitochondrial Dysfunction. Mol Cell. 2018; 69:58193 e7. [PubMed: 29452638]

Gilkes, Daniele M; Chaturvedi, Pallavi; Bajpai, Saumendra; Wong, Carmen Chak-Lui; Wei, Hong; Pitcairn, Stephen; Hubbi, Maimon E; Wirtz, Denis; Semenza, Gregg L. Collagen Prolyl Hydroxylases are Essential for Breast Cancer Metastasis. Cancer Res. 2013; 73:3285-96. [PubMed: 23539444]

Gilkes, Daniele M; Semenza, Gregg L; Wirtz, Denis. Hypoxia and the extracellular matrix: drivers of tumour metastasis. Nat Rev Cancer. 2014; 14:430-39. [PubMed: 24827502]

Hanahan D, Weinberg RA. Hallmarks of cancer: the next generation. Cell. 2011; 144:646-74. [PubMed: 21376230]

Hensley, Christopher T; Faubert, Brandon; Yuan, Qing; Lev-Cohain, Naama; Jin, Eunsook; Kim, Jiyeon; Jiang, Lei; Ko, Bookyung; Skelton, Rachael; Loudat, Laurin; Wodzak, Michelle; , et al. Metabolic Heterogeneity in Human Lung Tumors. Cell. 2016; 164:681-94. [PubMed: 26853473]

Herkenne S, Ek O, Zamberlan M, Pellattiero A, Chergova M, Chivite I, Novotna E, Rigoni G, Fonseca TB, Samardzic D, Agnellini A, et al. Developmental and Tumor Angiogenesis Requires the Mitochondria-Shaping Protein Opa1. Cell Metab. 2020; 31:987-1003 e8. [PubMed: 32315597]

Ihrlund LS, Hernlund E, Khan O, Shoshan MC. 3-Bromopyruvate as inhibitor of tumour cell energy metabolism and chemopotentiator of platinum drugs. Mol Oncol. 2008; 2:94-101. [PubMed: 19383331]

Ishikawa K, Takenaga K, Akimoto M, Koshikawa N, Yamaguchi A, Imanishi H, Nakada K, Honma Y, Hayashi J. ROS-generating mitochondrial DNA mutations can regulate tumor cell metastasis. Science. 2008; 320:661-4. [PubMed: 18388260] 
Jiang, Lei; Shestov, Alexander A; Swain, Pamela; Yang, Chendong; Parker, Seth J; Wang, Qiong A; Terada, Lance S; Adams, Nicholas D; McCabe, Michael T; Pietrak, Beth; Schmidt, Stan; , et al. Reductive carboxylation supports redox homeostasis during anchorage-independent growth. Nature. 2016; 532:255-58. [PubMed: 27049945]

Kamien B, Ronan A, Poke G, Sinnerbrink I, Baynam G, Ward M, Gibson WT, Dudding-Byth T, Scott RJ. A Clinical Review of Generalized Overgrowth Syndromes in the Era of Massively Parallel Sequencing. Mol Syndromol. 2018; 9:70-82. [PubMed: 29593474]

Kanarek N, Petrova B, Sabatini DM. Dietary modifications for enhanced cancer therapy. Nature. 2020; 579:507-17. [PubMed: 32214253]

Karachaliou N, Pilotto S, Teixido C, Viteri S, Gonzalez-Cao M, Riso A, Morales-Espinosa D, Molina MA, Chaib I, Santarpia M, Richardet E, et al. Melanoma: oncogenic drivers and the immune system. Ann Transl Med. 2015; 3:265. [PubMed: 26605311]

Kelley DE, Mandarino LJ. Fuel selection in human skeletal muscle in insulin resistance: a reexamination. Diabetes. 2000; 49:677-83. [PubMed: 10905472]

Keshet R, Szlosarek P, Carracedo A, Erez A. Rewiring urea cycle metabolism in cancer to support anabolism. Nat Rev Cancer. 2018; 18:634-45. [PubMed: 30194362]

Kimmelman AC, White E. Autophagy and Tumor Metabolism. Cell Metab. 2017; 25:1037-43. [PubMed: 28467923]

Knott, Simon RV; Wagenblast, Elvin; Khan, Showkhin; Kim, Sun Y; Soto, Mar; Wagner, Michel; Turgeon, Marc-Olivier; Fish, Lisa; Erard, Nicolas; Gable, Annika L; Maceli, Ashley R; , et al. Asparagine bioavailability governs metastasis in a model of breast cancer. Nature. 2018; 554:378. [PubMed: 29414946]

Kuntz EM, Baquero P, Michie AM, Dunn K, Tardito S, Holyoake TL, Helgason GV, Gottlieb E. Targeting mitochondrial oxidative phosphorylation eradicates therapy-resistant chronic myeloid leukemia stem cells. Nat Med. 2017; 23:1234-40. [PubMed: 28920959]

Kurelac I, Iommarini L, Vatrinet R, Amato LB, De Luise M, Leone G, Girolimetti G, Umesh Ganesh $\mathrm{N}$, Bridgeman VL, Ombrato L, Columbaro M, et al. Inducing cancer indolence by targeting mitochondrial Complex I is potentiated by blocking macrophage-mediated adaptive responses. Nat Commun. 2019; 10:903. [PubMed: 30796225]

Labuschagne, Christiaan F; Cheung, Eric C; Blagih, Julianna; Domart, Marie-Charlotte; Vousden, Karen H. Cell Clustering Promotes a Metabolic Switch that Supports Metastatic Colonization. Cell Metab. 2019; 30:720-34 e5. [PubMed: 31447323]

LaGory EL, Wu C, Taniguchi CM, Ding CC, Chi JT, von Eyben R, Scott DA, Richardson AD, Giaccia AJ. Suppression of PGC-1alpha Is Critical for Reprogramming Oxidative Metabolism in Renal Cell Carcinoma. Cell Rep. 2015; 12:116-27. [PubMed: 26119730]

Le Gal K, Ibrahim MX, Wiel C, Sayin VI, Akula MK, Karlsson C, Dalin MG, Akyurek LM, Lindahl P, Nilsson J, Bergo MO. Antioxidants can increase melanoma metastasis in mice. Sci Transl Med. 2015; 7

LeBleu VS, O'Connell JT, Gonzalez Herrera KN, Wikman H, Pantel K, Haigis MC, de Carvalho FM, Damascena A, Domingos Chinen LT, Rocha RM, Asara JM, et al. PGC-1alpha mediates mitochondrial biogenesis and oxidative phosphorylation in cancer cells to promote metastasis. Nat Cell Biol. 2014; 16:992-1003. [PubMed: 25241037]

Lin J, Xia L, Liang J, Han Y, Wang H, Oyang L, Tan S, Tian Y, Rao S, Chen X, Tang Y, et al. The roles of glucose metabolic reprogramming in chemo- and radio-resistance. J Exp Clin Cancer Res. 2019; 38:218. [PubMed: 31122265]

Liu L, Ulbrich J, Muller J, Wustefeld T, Aeberhard L, Kress TR, Muthalagu N, Rycak L, Rudalska R, Moll R, Kempa S, et al. Deregulated MYC expression induces dependence upon AMPK-related kinase 5. Nature. 2012; 483:608-12. [PubMed: 22460906]

Long Y, Tsai WB, Chang JT, Estecio M, Wangpaichitr M, Savaraj N, Feun LG, Chen HH, Kuo MT. Cisplatin-induced synthetic lethality to arginine-starvation therapy by transcriptional suppression of ASS1 is regulated by DEC1, HIF-1alpha, and c-Myc transcription network and is independent of ASS1 promoter DNA methylation. Oncotarget. 2016; 7:82658-70. [PubMed: 27765932] 
Long Y, Tsai WB, Wangpaichitr M, Tsukamoto T, Savaraj N, Feun LG, Kuo MT. Arginine deiminase resistance in melanoma cells is associated with metabolic reprogramming, glucose dependence, and glutamine addiction. Mol Cancer Ther. 2013; 12:2581-90. [PubMed: 23979920]

Loo, Jia Min; Scherl, Alexis; Nguyen, Alexander; Man, Fung Ying; Weinberg, Ethan; Zeng, Zhaoshi; Saltz, Leonard; Paty, Philip B; Tavazoie, Sohail F. Extracellular Metabolic Energetics Can Promote Cancer Progression. Cell. 2015; 160:393-406. [PubMed: 25601461]

Luo C, Lim JH, Lee Y, Granter SR, Thomas A, Vazquez F, Widlund HR, Puigserver P. A PGC1alphamediated transcriptional axis suppresses melanoma metastasis. Nature. 2016; 537:422-26. [PubMed: 27580028]

Luo G, Liu N. An integrative theory for cancer (Review). Int J Mol Med. 2019; 43:647-56. [PubMed: 30483756]

Ma L, Zong X. Metabolic Symbiosis in Chemoresistance: Refocusing the Role of Aerobic Glycolysis. Front Oncol. 2020; 10:5. [PubMed: 32038983]

Magaway C, Kim E, Jacinto E. Targeting mTOR and Metabolism in Cancer: Lessons and Innovations. Cells. 2019; 8

Masgras I, Sanchez-Martin C, Colombo G, Rasola A. The Chaperone TRAP1 As a Modulator of the Mitochondrial Adaptations in Cancer Cells. Front Oncol. 2017; 7:58. [PubMed: 28405578]

McIntyre A, Harris AL. Metabolic and hypoxic adaptation to anti-angiogenic therapy: a target for induced essentiality. EMBO Mol Med. 2015; 7:368-79. [PubMed: 25700172]

Momcilovic M, Jones A, Bailey ST, Waldmann CM, Li R, Lee JT, Abdelhady G, Gomez A, Holloway T, Schmid E, Stout D, et al. In vivo imaging of mitochondrial membrane potential in non-smallcell lung cancer. Nature. 2019; 575:380-84. [PubMed: 31666695]

Mowers EE, Sharifi MN, Macleod KF. Autophagy in cancer metastasis. Oncogene. 2017; 36:1619-30. [PubMed: 27593926]

Papagiannakopoulos T, Bauer MR, Davidson SM, Heimann M, Subbaraj L, Bhutkar A, Bartlebaugh J, Vander Heiden MG, Jacks T. Circadian Rhythm Disruption Promotes Lung Tumorigenesis. Cell Metab. 2016; 24:324-31. [PubMed: 27476975]

Parker SJ, Amendola CR, Hollinshead KER, Yu Q, Yamamoto K, Encarnación-Rosado J, Rose RE, LaRue MM, Sohn ASW, Biancur DE, Paulo JA, et al. Selective Alanine Transporter Utilization Creates a Targetable Metabolic Niche in Pancreatic Cancer. Cancer Discov. 2020; 10:1018-37. [PubMed: 32341021]

Parmenter TJ, Kleinschmidt M, Kinross KM, Bond ST, Li J, Kaadige MR, Rao A, Sheppard KE, Hugo W, Pupo GM, Pearson RB, et al. Response of BRAF-mutant melanoma to BRAF inhibition is mediated by a network of transcriptional regulators of glycolysis. Cancer Discov. 2014; 4:423-33. [PubMed: 24469106]

Pascual, Gloria; Avgustinova, Alexandra; Mejetta, Stefania; Martín, Mercè; Castellanos, Andrés; Attolini, Camille Stephan-Otto; Berenguer, Antoni; Prats, Neus; Toll, Agustí; Hueto, Juan Antonio; Bescós, Coro; , et al. Targeting metastasis-initiating cells through the fatty acid receptor CD36. Nature. 2017; 541:41-45. [PubMed: 27974793]

Pisarsky L, Bill R, Fagiani E, Dimeloe S, Goosen RW, Hagmann J, Hess C, Christofori G. Targeting Metabolic Symbiosis to Overcome Resistance to Anti-angiogenic Therapy. Cell Rep. 2016; 15:1161-74. [PubMed: 27134168]

Piskounova E, Agathocleous M, Murphy MM, Hu Z, Huddlestun SE, Zhao Z, Leitch AM, Johnson TM, DeBerardinis RJ, Morrison SJ. Oxidative stress inhibits distant metastasis by human melanoma cells. Nature. 2015a; 527:186-91. [PubMed: 26466563]

Piskounova, Elena; Agathocleous, Michalis; Murphy, Malea M; Hu, Zeping; Huddlestun, Sara E; Zhao, Zhiyu; Leitch, AMarilyn; Johnson, Timothy M; DeBerardinis, Ralph J; Morrison, Sean J. Oxidative stress inhibits distant metastasis by human melanoma cells. Nature. 2015b; 12:186-91.

Porporato PE, Payen VL, Perez-Escuredo J, De Saedeleer CJ, Danhier P, Copetti T, Dhup S, Tardy M, Vazeille T, Bouzin C, Feron O, et al. A mitochondrial switch promotes tumor metastasis. Cell Rep. 2014; 8:754-66. [PubMed: 25066121]

Rabinovich S, Adler L, Yizhak K, Sarver A, Silberman A, Agron S, Stettner N, Sun Q, Brandis A, Helbling D, Korman S, et al. Diversion of aspartate in ASS1-deficient tumours fosters de novo pyrimidine synthesis. Nature. 2015; 527:379-83. [PubMed: 26560030] 
Reznik E, Wang Q, La K, Schultz N, Sander C. Mitochondrial respiratory gene expression is suppressed in many cancers. Elife. 2017; 6

Saber SH, Ali HEA, Gaballa R, Gaballah M, Ali HI, Zerfaoui M, Abd Elmageed ZY. Exosomes are the Driving Force in Preparing the Soil for the Metastatic Seeds: Lessons from the Prostate Cancer. Cells. 2020; 9

Schafer ZT, Grassian AR, Song L, Jiang Z, Gerhart-Hines Z, Irie HY, Gao S, Puigserver P, Brugge JS. Antioxidant and oncogene rescue of metabolic defects caused by loss of matrix attachment. Nature. 2009; 461:109-13. [PubMed: 19693011]

Sciacovelli M, Frezza C. Oncometabolites: Unconventional triggers of oncogenic signalling cascades. Free Radic Biol Med. 2016; 100:175-81. [PubMed: 27117029]

Sciacovelli M, Frezza C. Metabolic reprogramming and epithelial-to-mesenchymal transition in cancer. FEBS J. 2017; 284:3132-44. [PubMed: 28444969]

Sciacovelli, Marco; Schmidt, Christina; Maher, Eamonn R; Frezza, Christian. Metabolic Drivers in Hereditary Cancer Syndromes. Annual Review of Cancer Biology. 2020; 4:77-97.

Slawson C, Copeland RJ, Hart GW. O-GlcNAc signaling: a metabolic link between diabetes and cancer? Trends Biochem Sci. 2010; 35:547-55. [PubMed: 20466550]

Snyder V, Reed-Newman TC, Arnold L, Thomas SM, Anant S. Cancer Stem Cell Metabolism and Potential Therapeutic Targets. Front Oncol. 2018; 8:203. [PubMed: 29922594]

Sousa CM, Biancur DE, Wang X, Halbrook CJ, Sherman MH, Zhang L, Kremer D, Hwang RF, Witkiewicz AK, Ying H, Asara JM, et al. Pancreatic stellate cells support tumour metabolism through autophagic alanine secretion. Nature. 2016; 536:479-83. [PubMed: 27509858]

Srinivas US, Tan BWQ, Vellayappan BA, Jeyasekharan AD. ROS and the DNA damage response in cancer. Redox Biol. 2019; 25

Tasdogan A, Faubert B, Ramesh V, Ubellacker JM, Shen B, Solmonson A, Murphy MM, Gu Z, Gu W, Martin M, Kasitinon SY, et al. Metabolic heterogeneity confers differences in melanoma metastatic potential. Nature. 2020; 577:115-20. [PubMed: 31853067]

Tomasetti M, Nocchi L, Staffolani S, Manzella N, Amati M, Goodwin J, Kluckova K, Nguyen M, Strafella E, Bajzikova M, Peterka M, et al. MicroRNA-126 suppresses mesothelioma malignancy by targeting IRS1 and interfering with the mitochondrial function. Antioxid Redox Signal. 2014; 21:2109-25. [PubMed: 24444362]

Torrano V, Valcarcel-Jimenez L, Cortazar AR, Liu X, Urosevic J, Castillo-Martin M, Fernandez-Ruiz S, Morciano G, Caro-Maldonado A, Guiu M, Zuniga-Garcia P, et al. The metabolic co-regulator PGC1alpha suppresses prostate cancer metastasis. Nat Cell Biol. 2016; 18:645-56. [PubMed: 27214280]

Triki, Mouna; Rinaldi, Gianmarco; Planque, Melanie; Broekaert, Dorien; Winkelkotte, Alina M; Maier, Carina R; Raman, Sudha Janaki; Vandekeere, Anke; Elsen, Joke Van; Orth, Martin F; Grünewald, Thomas GP; , et al. mTOR Signaling and SREBP Activity Increase FADS2 Expression and Can Activate Sapienate Biosynthesis. Cell Reports. 2020; 31

Vazquez F, Lim JH, Chim H, Bhalla K, Girnun G, Pierce K, Clish CB, Granter SR, Widlund HR, Spiegelman BM, Puigserver P. PGC1alpha expression defines a subset of human melanoma tumors with increased mitochondrial capacity and resistance to oxidative stress. Cancer Cell. 2013; 23:287-301. [PubMed: 23416000]

Vriens, Kim; Christen, Stefan; Parik, Sweta; Broekaert, Dorien; Yoshinaga, Kazuaki; Talebi, Ali; Dehairs, Jonas; Escalona-Noguero, Carmen; Schmieder, Roberta; Cornfield, Thomas; Charlton, Catriona; , et al. Evidence for an alternative fatty acid desaturation pathway increasing cancer plasticity. Nature. 2019; 566:403-06. [PubMed: 30728499]

Warburg O. On the origin of cancer cells. Science. 1956; 123:309-14. [PubMed: 13298683]

Warburg O, Wind F, Negelein E. The Metabolism of Tumors in the Body. J Gen Physiol. 1927; 8:51930. [PubMed: 19872213]

Weinberg F, Hamanaka R, Wheaton WW, Weinberg S, Joseph J, Lopez M, Kalyanaraman B, Mutlu GM, Budinger GR, Chandel NS. Mitochondrial metabolism and ROS generation are essential for Kras-mediated tumorigenicity. Proc Natl Acad Sci U S A. 2010; 107:8788-93. [PubMed: 20421486] 
Xiao Z, Dai Z, Locasale JW. Metabolic landscape of the tumor microenvironment at single cell resolution. Nat Commun. 2019; 10

Yang L, Shi P, Zhao G, Xu J, Peng W, Zhang J, Zhang G, Wang X, Dong Z, Chen F, Cui H. Targeting cancer stem cell pathways for cancer therapy. Signal Transduct Target Ther. 2020; 5:8. [PubMed: 32296030]

Yun J, Rago C, Cheong I, Pagliarini R, Angenendt P, Rajagopalan H, Schmidt K, Willson JK, Markowitz S, Zhou S, Diaz LA Jr, et al. Glucose deprivation contributes to the development of KRAS pathway mutations in tumor cells. Science. 2009; 325:1555-9. [PubMed: 19661383]

Zhang G, Frederick DT, Wu L, Wei Z, Krepler C, Srinivasan S, Chae YC, Xu X, Choi H, Dimwamwa $\mathrm{E}$, Ope $\mathrm{O}$, et al. Targeting mitochondrial biogenesis to overcome drug resistance to MAPK inhibitors. J Clin Invest. 2016; 126:1834-56. [PubMed: 27043285]

Zois CE, Harris AL. Glycogen metabolism has a key role in the cancer microenvironment and provides new targets for cancer therapy. J Mol Med (Berl). 2016; 94:137-54. [PubMed: 26882899] 


\section{Significance}

Recognizing cancer dynamic metabolic adaptability as an entity can lead to targeted therapy that is expected to decrease drug resistance. 


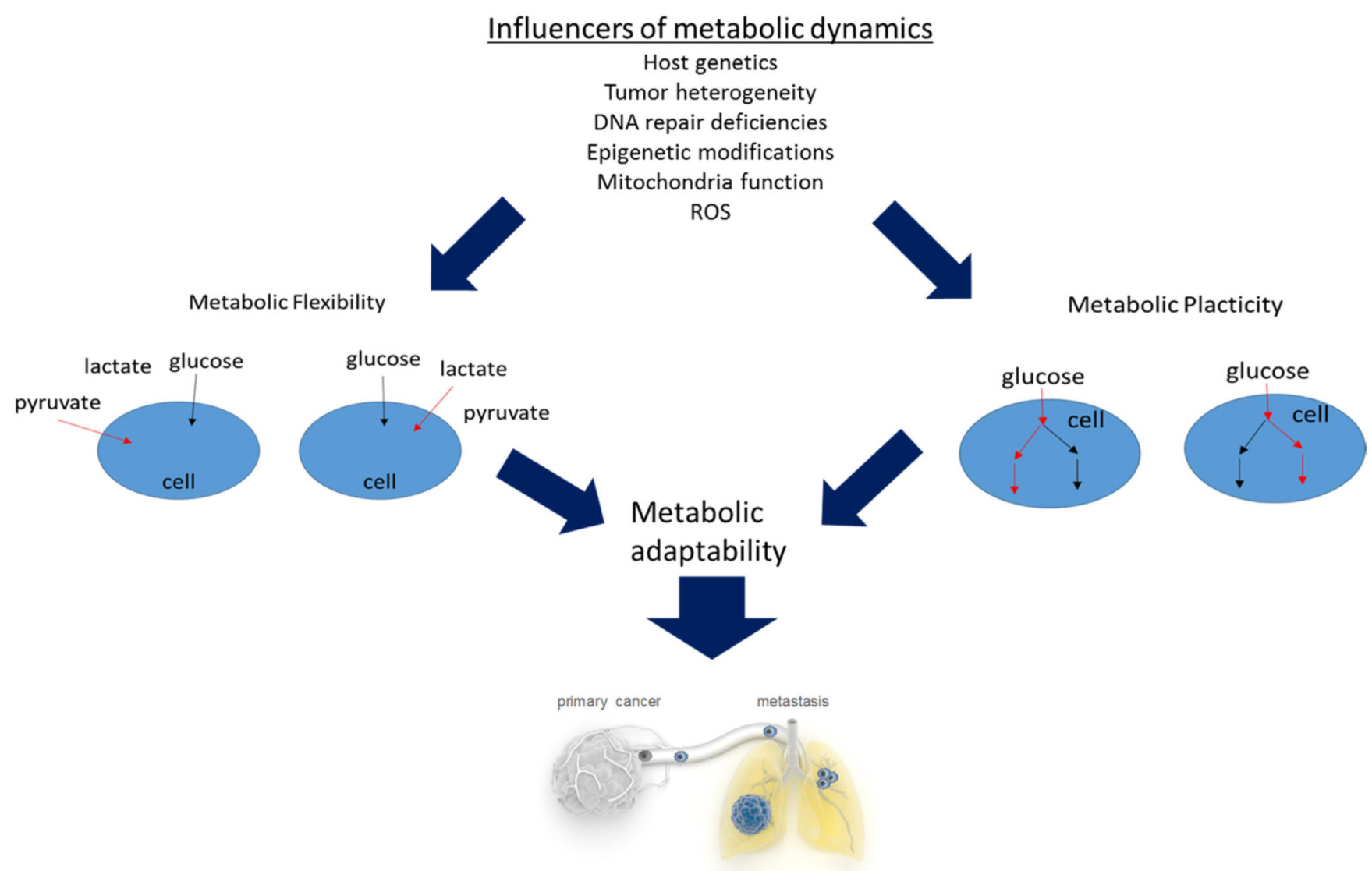

Figure 1. Metabolic flexibility and plasticity determine tumour metabolic adaptability. Multiple features affect tumour metabolic dynamics as exemplified by its flexibility and plasticity that enable its progression via metabolic adaptability to changing environmental cues. 


\section{adaptation scenario}

\section{pre-adaptation scenario}

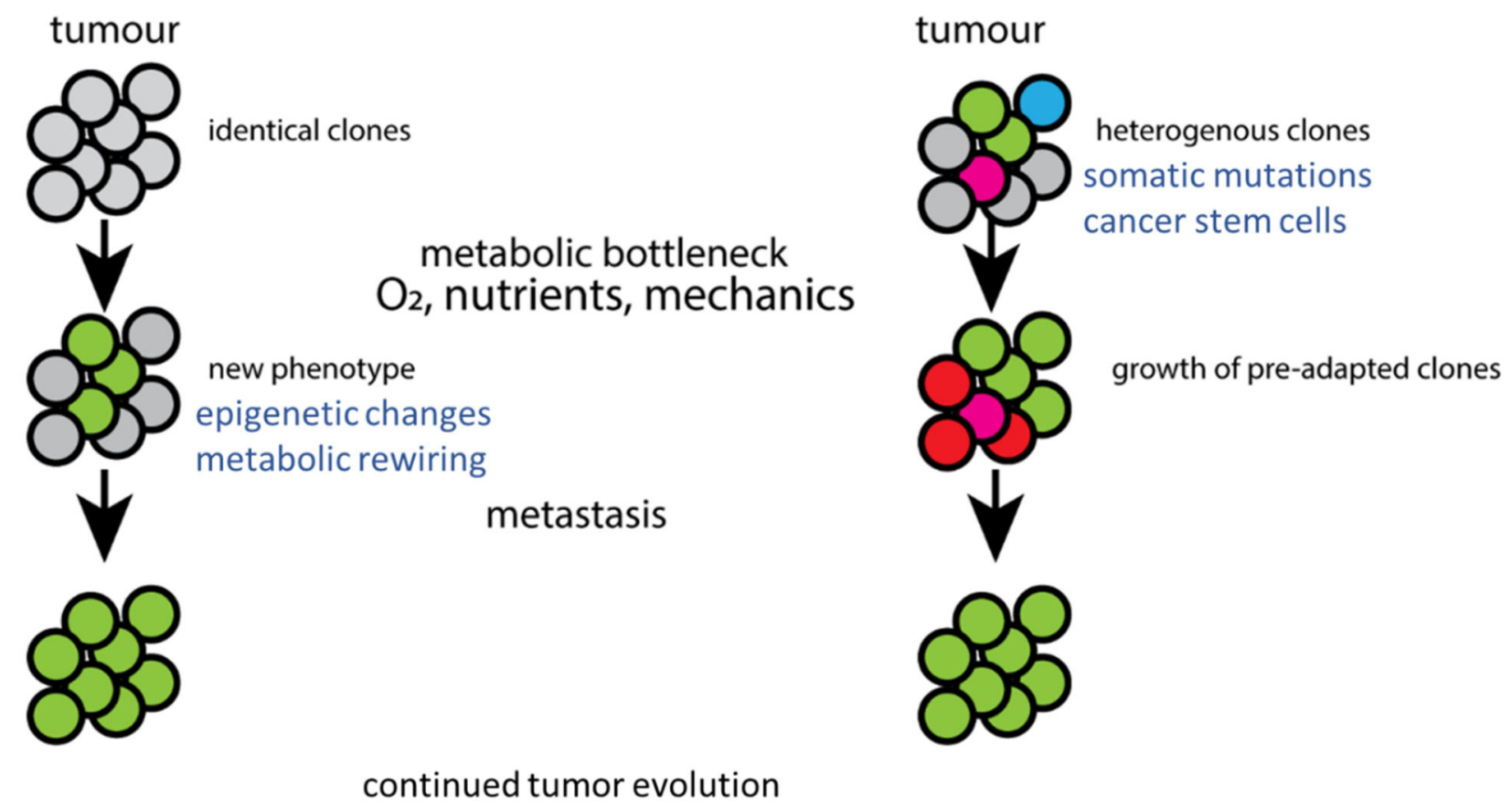

Figure 2. Two potential scenarios that promote tumour evolution.

Primary tumour heterogeneity can evolve through changes induced by different metabolic deprivations (adaptation), or exist and proliferate following selection for fitness (preadaptation). 


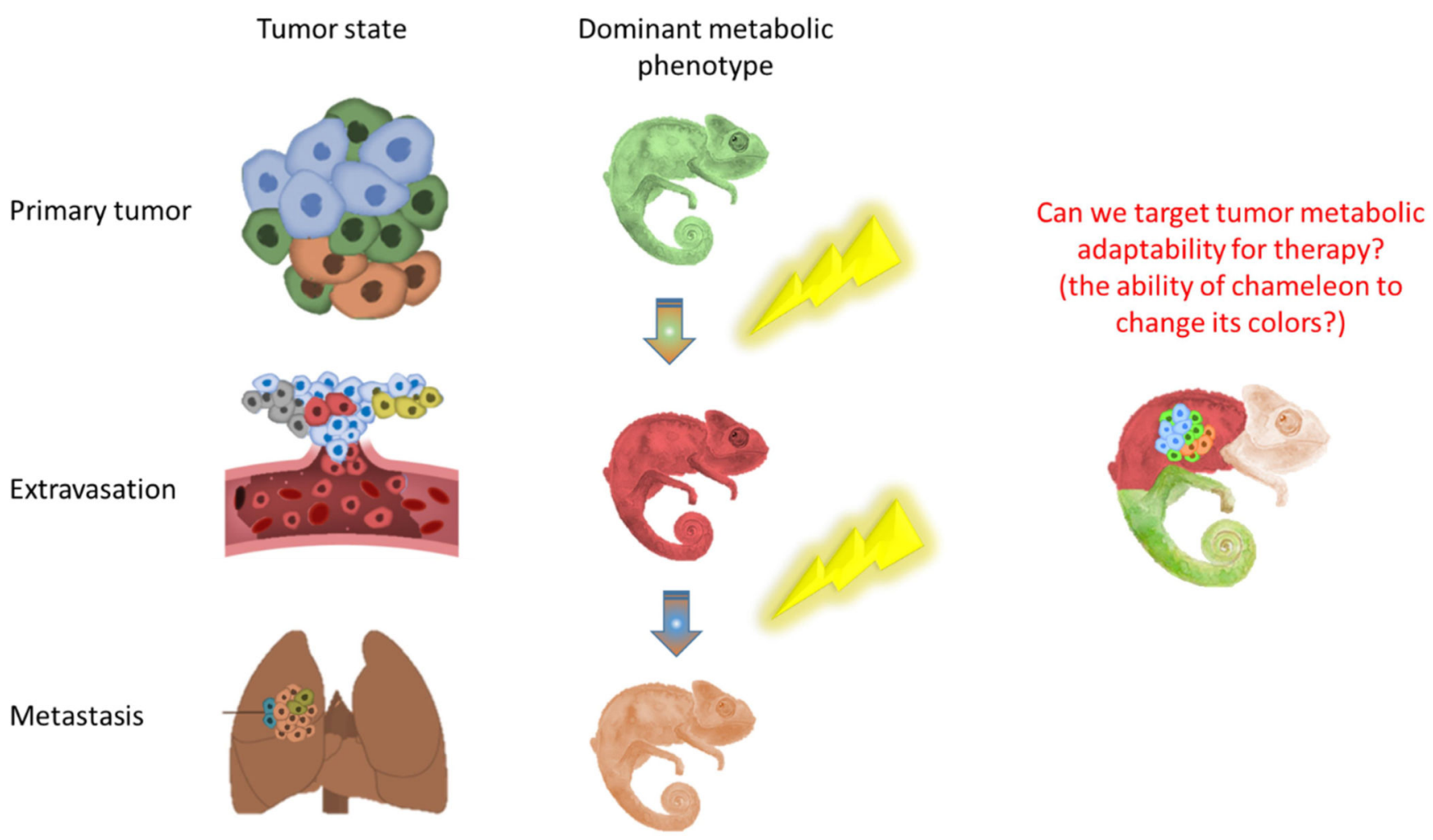

Figure 3. Schematic demonstration of the metabolic changes that accompany tumour progression.

Targeting tumour potential for metabolic adaptability can be a therapeutic strategy against tumour resistance. 
Table 1

Metabolic plasticity differs among different cancers during cancer progression.

\begin{tabular}{|c|c|c|c|c|}
\hline Tumour type & Primary & Circulating & Metastasis & References \\
\hline Breast & Oxidative & OXPHOS increase & OXPHOS increase & $\begin{array}{c}\text { (Andrzejewski, Klimcakova, Johnson, Tabaries, et al. } \\
\text { 2017); (LeBleu et al. 2014) }\end{array}$ \\
\hline Melanoma & Oxidative & $\begin{array}{c}\text { OXPHOS } \\
\text { suppression }\end{array}$ & Oxidative & (Luo et al. 2016) \\
\hline Prostate, Renal & Glycolytic & & OXPHOS suppression & (Torrano et al. 2016; LaGory et al. 2015) \\
\hline
\end{tabular}

